\title{
Absolute Myocardial Blood Flow After Elective Percutaneous Coronary Intervention Evaluated on Phase-Contrast Cine Cardiovascular Magnetic Resonance Imaging
}

\author{
Rikuta Hamaya, MD; Akinori Sugano, MD; Yoshihisa Kanaji, MD; Tadashi Fukuda, MD; \\ Yoshinori Kanno, MD; Taishi Yonetsu, MD; Eisuke Usui, MD; Masahiro Hoshino, MD; \\ Masahiro Hada, MD; Hiroaki Ohya, MD; Yohei Sumino, MD; Haruhito Yuki, MD; \\ Tadashi Murai, MD; Tetsumin Lee, MD; Tsunekazu Kakuta, MD, PhD
}

\begin{abstract}
Background: Few studies have documented changes in myocardial blood flow (MBF) after percutaneous coronary intervention $(\mathrm{PCl})$. Phase-contrast cine cardiovascular MRI (PC-CCMR) of the coronary sinus (CS) is a promising approach to quantify MBF. The aim of this study was to quantify CS flow (CSF) on PC-CCMR as a measure of volumetric MBF before and after elective PCI.

Methods and Results: We prospectively studied 34 patients with stable angina undergoing elective $\mathrm{PCl}$ for a single de novo lesion. Breath-hold PC-CCMR of CS was acquired to assess CSF and coronary flow reserve (CFR) at rest and during maximum hyperemia both before and after $\mathrm{PCl}$ (median, 3 days before $\mathrm{PCl}$ and 10 days after $\mathrm{PCl}$, respectively). In total, hyperemic CSF increased significantly after $\mathrm{PCl}$ (before $\mathrm{PCl}$, median, $2.3 \mathrm{~mL} / \mathrm{min} / \mathrm{g}$ [IQR, 1.5-3.2 $\mathrm{mL} / \mathrm{min} / \mathrm{g}$ ] after $\mathrm{PCl}, 3.0$ [1.8-3.7] mL/min/g), although 13 patients (38.2\%) had a decrease despite successful PCl and fractional flow reserve (FFR) improvement. Global CFR also significantly increased from a median of 2.5 (IQR, 1.5-3.5) to 3.4 (IQR, 2.1-4.2), whereas 12 patients had decreased CFR after PCl. Pre-PCI hyperemic CSF was the only independent factor of change in CSF following PCl.
\end{abstract}

Conclusions: Serial PC-CCMR of CS as a measure of change in absolute MBF is feasible. Uncomplicated PCI does not necessarily increase hyperemic global MBF, despite regional FFR improvement.

Key Words: Coronary flow reserve; Coronary sinus flow; Fractional flow reserve; Phase-contrast cine cardiovascular magnetic resonance imaging; Percutaneous coronary intervention

$\mathbf{P}$ ercutaneous coronary intervention (PCI) is used to increase coronary flow by modifying epicardial coronary artery stenosis. Fractional flow reserve (FFR)-guided PCI results in better outcomes compared with angiographic guidance, suggesting that FFR-guided PCI may increase coronary flow compared with angiography-guided PCI. ${ }^{1,2}$ The presence and extent of ischemia are considered the most important factors in coronary artery disease (CAD). Thus, use of PCI for epicardial lesions that do not increase coronary flow is questionable, and may expose patients to procedure-related and stent-related risks. ${ }^{1,3}$ The changes in volumetric coronary blood flow after elective PCI, however, remain unclear, because quantitative measurement of absolute coronary blood flow at the time of PCI is currently not possible. Nevertheless, the significant association of myocardial blood flow (MBF) with adverse clinical outcomes mandates a comprehensive approach to ischemic heart disease, including evaluation of absolute coronary flow impairment and pressure-derived

\section{FFR. ${ }^{2,4}$}

Phase-contrast cine cardiovascular magnetic resonance imaging (PC-CCMR) allows non-invasive quantification of coronary sinus (CS) blood flow, without use of ionizing radiation, radioactive tracers, gadolinium, or intravascular catheterization. ${ }^{5,6}$ The CS drains approximately $96 \%$ of the total MBF. Further, there is a good correlation of MBF with CS flow (CSF), indicating that PC-CCMR can estimate left ventricular (LV) MBF. ${ }^{6} \mathrm{PC}-\mathrm{CCMR}$ of the CS for absolute MBF and coronary flow reserve (CFR) has also been validated against positron emission tomography (PET). ${ }^{5,7,8}$ In the present study, we examined the increase in hyperemic MBF after elective PCI on PC-CCMR of the CS. Further, we evaluated the relationship of increased $\mathrm{MBF}$ to clinical and physiological indices including pre-PCI $\mathrm{MBF}, \mathrm{FFR}, \mathrm{CFR}$, and global coronary vascular resistance (CVR).

Received December 27, 2017; revised manuscript received February 17, 2018; accepted February 21, 2018; released online April 12, 2018 Time for primary review: 47 days

Cardiovascular Medicine, Tsuchiura Kyodo General Hospital, Tsuchiura, Japan

Mailing address: Tsunekazu Kakuta, MD, PhD, Department of Cardiovascular Medicine, Tsuchiura Kyodo General Hospital, 4-1-1 Otsuno, Tsuchiura 300-0028, Japan. E-mail: kaz@joy.email.ne.jp

ISSN-1346-9843 All rights are reserved to the Japanese Circulation Society. For permissions, please e-mail: cj@j-circ.or.jp 


\begin{tabular}{|c|c|c|c|c|}
\hline & $\begin{array}{l}\text { Total } \\
(n=34)\end{array}$ & $\begin{array}{l}\text { CSF increase } \\
\quad(n=21)\end{array}$ & $\begin{array}{l}\text { CSF decrease } \\
\qquad(n=13)\end{array}$ & P-value \\
\hline \multicolumn{5}{|l|}{ Demographics } \\
\hline Age (years) & $63.6 \pm 11.1$ & $61.6 \pm 10.2$ & $67.0 \pm 12.1$ & 0.17 \\
\hline Male & $29(85.3)$ & $18(85.7)$ & $11(84.6)$ & 0.93 \\
\hline Hypertension & $26(76.5)$ & $16(76.2)$ & $10(76.9)$ & 0.96 \\
\hline Diabetes mellitus & $12(35.3)$ & $6(28.6)$ & $6(46.2)$ & 0.30 \\
\hline Dyslipidemia & $18(52.9)$ & $12(57.1)$ & $6(46.2)$ & 0.53 \\
\hline Smoking & $18(52.9)$ & $11(52.4)$ & $7(53.8)$ & 0.93 \\
\hline Previous MI & $5(14.7)$ & $2(9.5)$ & $3(23.1)$ & 0.29 \\
\hline \multicolumn{5}{|l|}{ Biomarkers } \\
\hline Hs-cTnl (ng/L) & $5(3-17)$ & $4(2-13)$ & $9(3-20)$ & 0.25 \\
\hline NT-proBNP (pg/L) & $58(29-216)$ & $40(29-293)$ & $92(33-168)$ & 0.81 \\
\hline CRP (mg/dL) & $0.06(0.01-0.27)$ & $0.07(0.01-0.37)$ & $0.05(0.02-0.13)$ & 0.63 \\
\hline eGFR $\left(\mathrm{mL} / \mathrm{min} / 1.73 \mathrm{~m}^{2}\right)$ & $72.7(66.1-89.2)$ & $72.3(65.9-83.7)$ & $73.7(66.1-94.8)$ & 0.49 \\
\hline $\mathrm{PCl}$ targeted branch & & & & 0.60 \\
\hline LAD & $30(88.2)$ & $18(85.7)$ & $12(92.3)$ & \\
\hline LCX & $1(2.9)$ & $1(4.8)$ & $0(0)$ & \\
\hline $\mathrm{RCA}$ & $3(8.8)$ & $2(9.5)$ & $1(7.7)$ & \\
\hline Previous infarction of targeted branch & $1(2.9)$ & $1(4.8)$ & 0 & 0.32 \\
\hline \multicolumn{5}{|l|}{ QCA } \\
\hline Pre-PCl \% stenosis & $63.7(52.1-72.6)$ & $66.28(56.2-73.5)$ & $54.4(51.8-71.2)$ & 0.31 \\
\hline Pre-PCI reference diameter $(\mathrm{mm})$ & $2.7(2.4-3.1)$ & $2.7(2.3-3.1)$ & $2.7(2.4-3.1)$ & 0.69 \\
\hline Post-PCI \% stenosis & $14.0(10.8-20.9)$ & $13.8(10.9-21.1)$ & $14.2(9.7-20.4)$ & 0.82 \\
\hline Post-PCI reference diameter $(\mathrm{mm})$ & $2.9(2.7-3.2)$ & $3.1(2.7-3.3)$ & $2.8(2.5-3.0)$ & 0.079 \\
\hline \multicolumn{5}{|l|}{ Fractional flow reserve } \\
\hline Before PCl & $0.70(0.55-0.75)$ & $0.61(0.54-0.73)$ & $0.75(0.62-0.79)$ & 0.089 \\
\hline After PCl & $0.87(0.83-0.91)$ & $0.90(0.84-0.92)$ & $0.84(0.82-0.87)$ & 0.11 \\
\hline \multicolumn{5}{|l|}{ Hemodynamic data ${ }^{\dagger}$} \\
\hline $\mathrm{BP}$ at rest $(\mathrm{mmHg})$ & $99(91-106)$ & $95(91-107)$ & $100(91-108)$ & 0.67 \\
\hline BP during hyperemia $(\mathrm{mmHg})$ & $95(87-103)$ & $95(86-105)$ & $95(86-104)$ & 0.97 \\
\hline RPP at rest & $8,298(6,953-9,579)$ & $7,750(6,945-9,433)$ & $8,680(7,337-10,566)$ & 0.26 \\
\hline RPP during hyperemia & $9,963(7,930-11,657)$ & $9,933(7,930-11,213)$ & $11,070(8,199-12,286)$ & 0.44 \\
\hline \multicolumn{5}{|l|}{ CMR data } \\
\hline LVEDV (mL) & $127.6(113.6-143.8)$ & $129.3(121.1-148.2)$ & $126.9(108.8-137.7)$ & 0.29 \\
\hline LVESV (mL) & $53.1(42.3-67.4)$ & $51.7(43.4-67.1)$ & $56.1(39.7-71.3)$ & 0.94 \\
\hline LVEF (\%) & $56.8(52.2-62.8)$ & $60.2(55.0-62.6)$ & $55.9(50.9-64.1)$ & 0.78 \\
\hline LV mass $(\mathrm{g})$ & $91.6(81.1-109.2)$ & $92.3(80.2-116.2)$ & $90.1(76.9-96.4)$ & 0.29 \\
\hline
\end{tabular}

Data given as $n(\%)$, mean $\pm S D$, or median (IQR). tPre-PCI CMR measurement. BP, blood pressure; CMR, cardiovascular magnetic resonance imaging; CRP, C-reactive protein; CSF, coronary sinus flow; eGFR, estimated glomerular filtration rate; hs-cTnl, high-sensitivity cardiac troponin I; LAD, left anterior descending artery; LCX, left circumflex artery; LVEDV, left ventricular end-diastolic volume; LVEF, left ventricular ejection fraction; LVESV, left ventricular end-systolic volume; MI, myocardial infarction; NT-proBNP, N-terminal pro-brain natriuretic peptide; PCI, percutaneous coronary intervention; QCA, quantitative coronary angiography; RCA, right coronary artery; RPP, rate-pressure product.

\section{Methods}

\section{Subjects}

We prospectively, but non-consecutively, investigated physiological data collected from 38 patients scheduled for elective PCI with stable CAD and who underwent pre- and post-PCI PC-CCMR at Tsuchiura Kyodo General Hospital from April 2015 to June 2017. Inclusion criteria were age $>20$ years and detection of an identifiable, de novo single culprit lesion located at the proximal portion of a native coronary artery. Stable CAD was defined as no change in the frequency, duration, or intensity of angina symptoms $\leq 6$ weeks before PCI. The target lesion was identified on a combination of coronary angiograms, electrocardiogram (ECG), scintigram, perfusion cardiac magnetic resonance imaging, or FFR measurements. All included patients had angina, documented myocardial ischemia, or both. Exclusion criteria were angiographically significant left main disease, previous coronary artery bypass surgery, atrial fibrillation, renal insufficiency with baseline serum creatinine $>1.5 \mathrm{mg} / \mathrm{dL}$ or on dialysis, acute coronary syndrome, cardiogenic shock, congestive heart failure, a totally occluded culprit lesion, visible collateral development, or difficulty in culprit lesion identification. Patients with an impaired systolic ejection fraction $(<50 \%)$ were also excluded. The study protocol was approved by the institutional review board, and all patients provided written informed consent before CMR and PCI. 


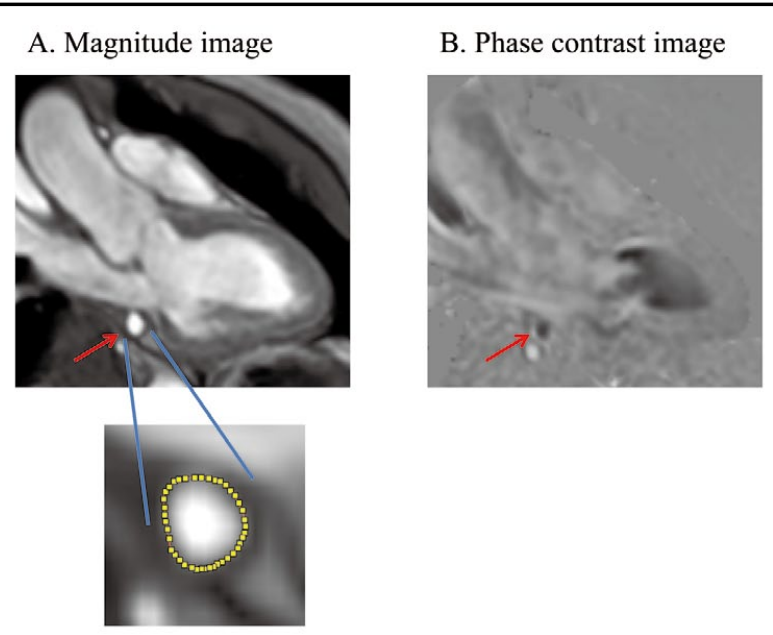

C. Curve of coronary sinus blood flow

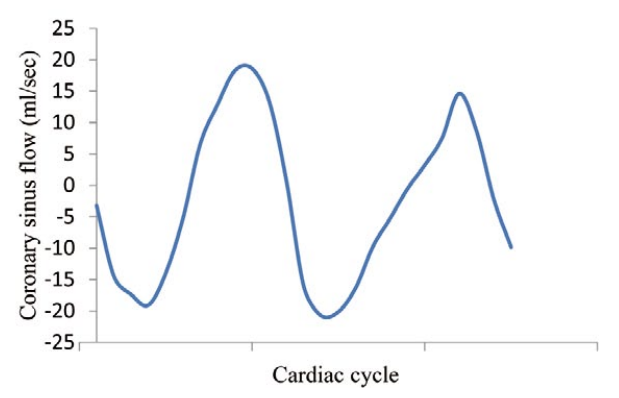

Figure 1. Representative case of phase-contrast cine cardiovascular magnetic resonance measurement. (A) Magnitude image and (B) phase-contrast image of the coronary sinus (CS); inset, CS tracing; arrows, blood flow in the CS. (C) Velocity curve of CS flow during maximum hyperemia.

\section{Cardiac Catheterization}

Each patient initially underwent standard selective coronary angiography for assessment of coronary anatomy via the radial artery using a 5-F system. Quantitative coronary angiography analysis was performed using a CMS-MEDIS system (Medis Medical Imaging Systems, Leiden, Netherlands). All patients received bolus heparin injection (5,000 IU) before catheterization, and an additional bolus injection (2,000 IU) every hour if the procedure was $>1 \mathrm{~h}$ for both diagnostic and interventional catheterization. An i.c. bolus injection of nitroglycerin $(0.2 \mathrm{mg})$ was given at the start of the procedure and repeated every $30 \mathrm{~min}$. Eligible patients were subsequently scheduled for pre-PCI PC-CCMR of the CS and elective PCI. All eligible patients had dual antiplatelet treatment $\geq 24 \mathrm{~h}$ before PCI. PCI was performed using a 6-F system via the radial artery. All patients underwent successful PCI with coronary stent implantation (drug-eluting, 100\%). The type of stent and strategy were determined by the interventionist. To avoid aggressive stent expansion, online quantitative coronary angiography was used to determine the correct stent size. Successful PCI was defined as $<20 \%$ residual stenosis with thrombolysis in myocardial infarction grade 3 flow, no side branch occlusion or distal embolization, and no PCIrelated myocardial infarction.

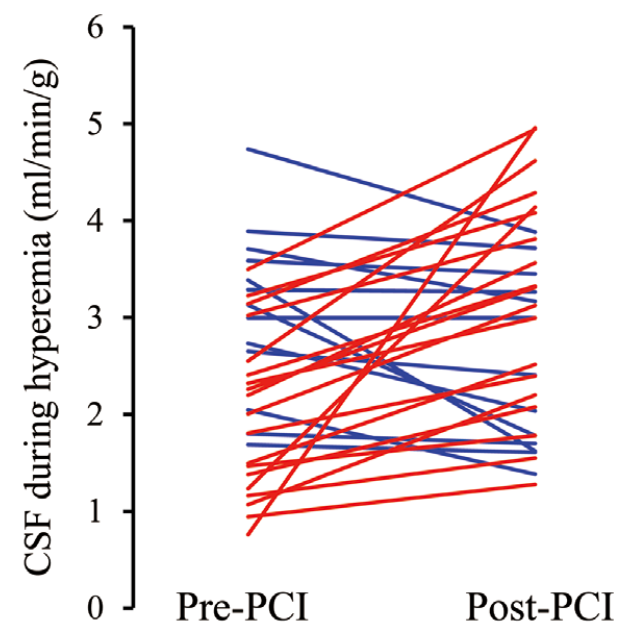

Figure 2. Change in hyperemic coronary sinus flow (CSF) after percutaneous coronary intervention (PCI).

\section{Intracoronary Physiological Indices}

Before and after elective stenting, FFR was determined using a RadiAnalyzer Xpress instrument with a Certus coronary pressure wire (St. Jude Medical, St. Paul, MN, USA), as reported. ${ }^{9}$ FFR was calculated as the ratio of distal coronary pressure to proximal coronary pressure at stable hyperemia induced by i.v. adenosine $(140 \mu \mathrm{g} / \mathrm{kg} / \mathrm{min}$ via a central vein). All patients were strictly instructed to refrain from caffeinated beverages for $>24 \mathrm{~h}$ before catheterization.

\section{CMR Acquisition and Cine CMR}

CMR acquisition was performed both before PCI (median, 3 days; range, 2-5 days before PCI) and after PCI (median, 10 days; range, $8-13$ days) to evaluate serial changes. Images were acquired on a 1.5-Tesla scanner (Philips Achieva; Philips Medical Systems, Best, the Netherlands) with 32-channel cardiac coils. Cardiac gating and heart rate were recorded with a vecto-cardiogram device. CCMR was performed using a retrospectively gated steady-state free precession sequence. Twelve short-axis slices of the LV were acquired from apex to base. CCMR parameters were: repetition time, $4.1 \mathrm{~ms}$; echo time, $1.4 \mathrm{~ms}$; slice thickness, $6 \mathrm{~mm}$; flip angle, $55^{\circ}$; field of view, $350 \times 350 \mathrm{~mm}^{2}$; matrix size, $128 \times 128$; and 20 phases per cardiac cycle. LV mass and volumes were calculated from Simpson's rule using CMR data. ${ }^{8}$

\section{CSF Measurement}

The CS was identified in the atrioventricular groove using basal slices of the short-axis stack. The plane for flow measurement on PC-CCMR was perpendicular to the CS at approximately $1-2 \mathrm{~cm}$ from the ostium. ${ }^{\mathbf{8 1 0}}$ Velocity-encoded images were acquired with retrospective ECG gating during approximately 15 -s breath holds. Imaging parameters were: repetition time, $7.3 \mathrm{~ms}$; echo time, $4.4 \mathrm{~ms}$; flip angle, $10^{\circ}$; field of view, $250 \times 250 \mathrm{~mm}^{2}$; acquisition matrix, $128 \times 128 ; 20$ phases per cardiac cycle, encoding $50 \mathrm{~cm} / \mathrm{s}$; and slice thickness, $6 \mathrm{~mm}$. PC-CCMR of CS measurements were performed during adenosine infusion and at rest. Total CMR time for standard cine CMR and CSF 


\begin{tabular}{|c|c|c|c|c|}
\hline & Total & CSF increase & CSF decrease & P-value \\
\hline \multicolumn{5}{|l|}{ Before PCI } \\
\hline Corrected CSF at rest (mL/min) & $88.3(76.1-116.1)$ & $79.4(62.4-112.9)$ & $99.6(84.2-120.5)$ & 0.14 \\
\hline CSF during hyperemia (mL/min) & $205.1(169.1-263)$ & $180.3(141.2-252.1)$ & $255.5(194.1-314.3)$ & 0.037 \\
\hline Corrected CSF at rest $(\mathrm{mL} / \mathrm{min} / \mathrm{g})$ & $1.0(0.8-1.3)$ & $0.9(0.6-1.2)$ & $1.2(0.9-1.4)$ & 0.076 \\
\hline CSF during hyperemia $(\mathrm{mL} / \mathrm{min} / \mathrm{g})$ & $2.3(1.5-3.2)$ & $2.0(1.3-2.8)$ & $3.1(1.9-3.6)$ & 0.010 \\
\hline CFR & $2.5(1.5-3.5)$ & $2.1(1.5-3.5)$ & $2.7(2.0-3.5)$ & 0.55 \\
\hline Global CVR (mmHg/min/mL) & $0.46(0.34-0.62)$ & $0.51(0.37-0.76)$ & $0.35(0.29-0.56)$ & 0.043 \\
\hline \multicolumn{5}{|l|}{ After PCI } \\
\hline Corrected CSF at rest (mL/min) & $88.6(57.9-120.1)$ & $88.8(55.5-134.0)$ & $87.8(68.4-115.8)$ & 0.92 \\
\hline CSF during hyperemia (mL/min) & $250.6(180.7-354.8)$ & $262.8(245.4-377.9)$ & $181.1(142.8-293.0)$ & 0.019 \\
\hline Corrected CSF at rest $(\mathrm{mL} / \mathrm{min} / \mathrm{g})$ & $1.0(0.6-1.3)$ & $1.0(0.6-1.3)$ & $0.9(0.8-1.3)$ & 0.89 \\
\hline CSF during hyperemia $(\mathrm{mL} / \mathrm{min} / \mathrm{g})$ & $3.0(1.8-3.7)$ & $3.1(2.1-4.1)$ & $2.0(1.6-3.4)$ & 0.071 \\
\hline CFR & $3.4(2.1-4.2)$ & $3.9(2.2-4.6)$ & $2.8(1.4-3.7)$ & 0.056 \\
\hline Global CVR (mmHg/min/mL) & $0.37(0.25-0.54)$ & $0.31(0.25-0.40)$ & $0.54(0.36-0.70)$ & 0.006 \\
\hline \multicolumn{5}{|l|}{ Change after $\mathrm{PCl}$} \\
\hline Corrected CSF at rest (mL/min) & $-7.9(-28.6$ to 23.6$)$ & $8.5(-27.7$ to 27.5$)$ & $-11.3(-37.9$ to 5.7$)$ & 0.18 \\
\hline CSF during hyperemia (mL/min) & $50.3(-25.9$ to 108.4$)$ & $91.5(63.9-129.1)$ & $-41.1(-69.6$ to -17.4$)$ & $<0.001$ \\
\hline Corrected CSF at rest $(\mathrm{mL} / \mathrm{min} / \mathrm{g})$ & $-0.06(-0.35$ to 0.28$)$ & $0.02(-0.36$ to 0.33$)$ & $-0.11(-0.32$ to 0.10$)$ & 0.50 \\
\hline CSF during hyperemia $(\mathrm{mL} / \mathrm{min} / \mathrm{g})$ & $0.36(-0.19$ to 1.07$)$ & $0.92(0.49$ to 1.26$)$ & $-0.54(-0.78$ to -0.12$)$ & $<0.001$ \\
\hline CFR & $0.4(-0.3$ to 2.2$)$ & $1.1(0-2.5)$ & $-0.1(-0.7$ to 0.4$)$ & 0.018 \\
\hline Global CVR (mmHg/min/mL) & $-0.09(-0.17$ to 0.09$)$ & $-0.14(-0.38$ to -0.11$)$ & $0.09(0.04-0.23)$ & $<0.001$ \\
\hline
\end{tabular}

Data given as median (IQR). CFR, coronary flow reserve; CSF, coronary sinus flow; CVR, coronary vascular resistance; PC-CCMR, phase-contrast cine cardiovascular magnetic resonance imaging; $\mathrm{PCl}$, percutaneous coronary intervention.

measurement was approximately $10-15 \mathrm{~min}$.

\section{PC-CCMR Analysis}

CSF quantitative analysis on PC-CCMR was performed using proprietary software (Philips View Forum; Philips Medical Systems) in a blinded fashion by 2 expert researchers (Y. Kanaji, R.H). The CS contour was traced on the magnitude images throughout the cardiac cycle. CSF quantification was calculated by integrating the flow rates from each cardiac cycle and multiplying by mean heart rate during acquisition. We calculated CSF, CFR and CVR using the following formula. Given that resting MBF but not hyperemic MBF linearly correlates with rate pressure product (RPP), we corrected CSF only at rest using RPP:8,11,12

$\mathrm{RPP}=$ systolic blood pressure $(\mathrm{mmHg}) \times$ heart rate (beats $/ \mathrm{min}) ; \mathrm{CSF}(\mathrm{mL} / \mathrm{min} / \mathrm{g})=\mathrm{CSF}(\mathrm{mL} / \mathrm{min}) / \mathrm{LV}$ mass $(\mathrm{g})$; corrected $\mathrm{CSF}(\mathrm{cCSF})$ at rest $(\mathrm{mL} / \mathrm{min} / \mathrm{g})=\mathrm{CSF}$ at rest $(\mathrm{mL} / \mathrm{min} / \mathrm{g}) / \mathrm{RPP} \times 7,500 ; \mathrm{CFR}=\mathrm{CSF}$ during hyperemia $(\mathrm{mL} / \mathrm{min} / \mathrm{g}) / \mathrm{cCSF}$ at rest $(\mathrm{mL} / \mathrm{min} / \mathrm{g}) ; \mathrm{CVR}=$ mean arterial blood pressure $(\mathrm{mmHg}) / \mathrm{CSF}$ during hyperemia $(\mathrm{mL} / \mathrm{min})$.

\section{Statistical Analysis}

Data were analyzed as serial measurements before and after PCI. To examine serial changes in CSF, lesions were divided based on an increase (CSF increase group) or decrease (CSF decrease group) in hyperemic CSF $(\mathrm{mL} / \mathrm{min} / \mathrm{g}$ ) after PCI. Patient characteristics, angiographic data, and physiological data were compared between these groups. Statistical analysis was performed using JMP 11.2.0 (SAS Institute, Cary, NC, USA). Categorical data are expressed as absolute frequencies and percentages, and were compared using chi-squared or Fisher's exact tests, as appropriate. Continuous variables are expressed as mean \pm SD for normally distributed variables, or as median (IQR) for non-normally distributed variables, and compared using Student's t-test and Mann-Whitney U-test, respectively. Correlations between the two parameters were evaluated on linear regression. Predictors for hyperemic CSF decrease were assessed with binary logistic regression, and the associated variables on univariate analysis $(\mathrm{P} \leq 0.2)$ were included in the multivariate model. Receiver operating characteristic (ROC) curve analysis was used to determine the optimal cut-offs. Intra- and inter-observer variability was assessed using intraclass correlation coefficients (ICC). Reproducibility was also evaluated on Bland-Altman analysis. $\mathrm{P}<0.05$ indicated statistical significance.

\section{Results}

\section{Patient Characteristics}

Stenting was performed successfully in all patients. Post-PCI high-sensitivity cardiac troponin I elevation (hs-cTnI; $\geq 5$-fold the upper reference limit) was observed in 12 patients $(12 / 38 ; 31.6 \%)$ based on blood samples taken at $18.3 \pm 2.7 \mathrm{~h}$ after PCI. Given that no patients had ECG abnormalities, chest pain, or new echocardiographic wall motion abnormalities, these patients with isolated minor troponin elevation were included in further analysis. There was no significant relationship of post-PCI hs-cTnI with change in $\mathrm{CSF}(\mathrm{P}=0.52)$. From a total of 38 initially included patients, we excluded 2 patients presenting with atrioventricular block during adenosine treatment, and 2 patients with suboptimal CMR. Therefore, we evaluated data from 34 patients $(89.5 \%)$ for the final analysis. Patient baseline characteristics are listed in Table 1. All included culprit lesions had FFR $\leq 0.8$. Median pre-PCI and post-PCI FFR were 0.70 (IQR, 0.55-0.75) and 0.87 (IQR, 0.83-0.91), 


\section{A. Pre-PCI hyperemic CSF}

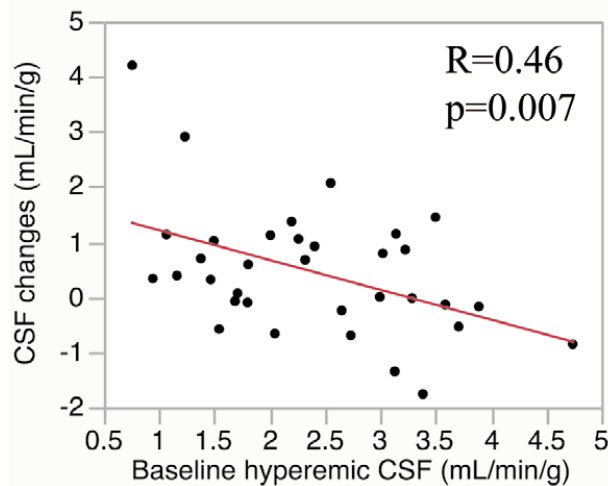

B. Pre-PCI CVR

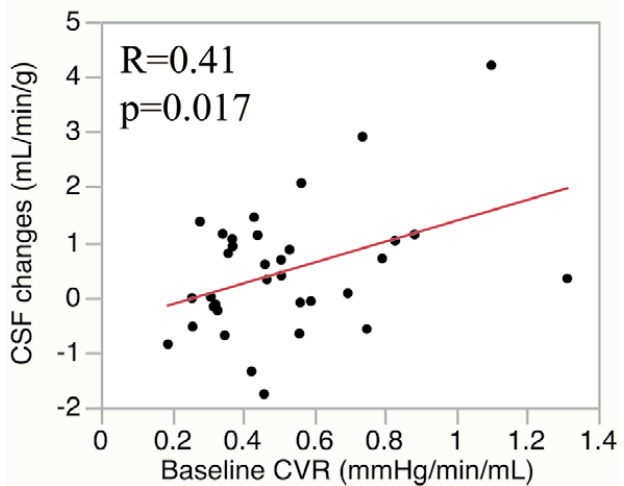

Figure 3. Change in hyperemic coronary sinus flow (CSF) after percutaneous coronary intervention (PCI) vs. (A) pre-PCI hyperemic CSF and (B) pre-PCI global coronary vascular resistance (CVR).

\begin{tabular}{|c|c|c|c|c|c|c|}
\hline & \multicolumn{3}{|c|}{ Univariate model } & \multicolumn{3}{|c|}{ Multivariate model } \\
\hline & OR & $95 \% \mathrm{Cl}$ & P-value & OR & $95 \% \mathrm{Cl}$ & P-value \\
\hline Age (per year) & 1.05 & $0.98-1.13$ & 0.17 & 1.03 & $0.95-1.12$ & 0.47 \\
\hline FFR (per 0.01 unit) & 1.03 & $0.97-1.12$ & 0.36 & & & \\
\hline Corrected CSF at rest (per mL/min/g) & 5.03 & $0.80-46.6$ & 0.11 & 1.49 & $0.14-18.9$ & 0.74 \\
\hline CSF during hyperemia (per $\mathrm{mL} / \mathrm{min} / \mathrm{g}$ ) & 3.16 & $1.37-9.06$ & 0.015 & 2.79 & $1.09-8.97$ & 0.031 \\
\hline
\end{tabular}

The multivariate model consisted of factors with $\mathrm{P} \leq 0.2$ on univariate analysis (age, corrected CSF at rest, and CSF during hyperemia). CSF, coronary sinus flow; FFR, fractional flow reserve; $\mathrm{PCl}$, percutaneous coronary intervention.

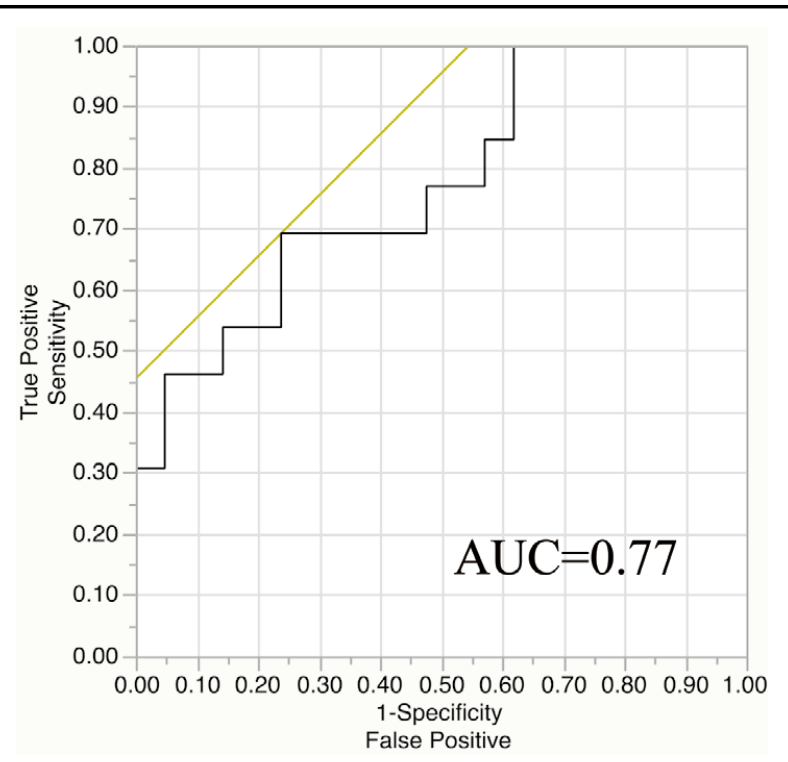

Figure 4. Receiver operating characteristic analysis for prediction of hyperemic coronary sinus flow (CSF) decrease after percutaneous coronary intervention $(\mathrm{PCl})$ by pre- $\mathrm{PCl}$ hyperemic CSF. The best cut-off of pre-PCI hyperemic CSF was $2.65 \mathrm{~mL} / \mathrm{min} / \mathrm{g}(95 \% \mathrm{Cl}: 1.4-9.1, \mathrm{P}=0.006)$. AUC, area under the curve. respectively, and all patients had increased FFR after PCI. Figure 1 shows a representative case of PC-CCMR CSF measurements.

\section{Hyperemic CSF Change After PCI}

Figure 2 shows the changes in hyperemic CSF following PCI. Median CSF during hyperemia increased from $205.1 \mathrm{~mL} / \mathrm{min}$ (IQR, $169.1-263 \mathrm{~mL} / \mathrm{min}$ ) to $250.6 \mathrm{~mL} / \mathrm{min}$ (IQR, $180.7-354.8 \mathrm{~mL} / \mathrm{min}$ ), or from $2.3 \mathrm{~mL} / \mathrm{min} / \mathrm{g}$ (IQR, $1.5-3.2 \mathrm{~mL} / \mathrm{min} / \mathrm{g})$ to $3.0 \mathrm{~mL} / \mathrm{min} / \mathrm{g}$ (IQR, $1.8-3.7 \mathrm{~mL} / \mathrm{min} / \mathrm{g})$ after PCI ( $\mathrm{P}<0.05$ for each), whereas 13 patients $(38.2 \%)$ showed a decrease. Median global CFR significantly increased from 2.5 (IQR, 1.5-3.5) to 3.4 (IQR, 2.1-4.2), while 12 patients had a decrease. Median CVR showed a trend towards a decrease following PCI $(0.46 \mathrm{mmHg} / \mathrm{min} / \mathrm{mL}$; IQR, $0.34-0.62 \mathrm{mmHg} / \mathrm{min} / \mathrm{mL}$ vs. $0.37 \mathrm{mmHg} / \mathrm{min} / \mathrm{mL}$, IQR, $0.25-0.54 \mathrm{mmHg} / \mathrm{min} / \mathrm{mL} ; \mathrm{P}=0.07$ ), while the increase was documented in 11 patients.

There were no differences in baseline characteristics including the prevalence of previous myocardial infarction between patients with (CSF increase group) and without (CSF decrease group) increased hyperemic CSF following PCI (Table 1). Table 2 lists CMR data acquired before and after PCI, and changes after PCI. The CSF decrease group had significantly higher median pre-PCI CSF $(3.1 \mathrm{~mL} / \mathrm{min} / \mathrm{g}$; IQR, $1.9-3.6 \mathrm{~mL} / \mathrm{min} / \mathrm{g}$ vs. $2.0 \mathrm{~mL} / \mathrm{min} / \mathrm{g}$, IQR, $1.3-2.8 \mathrm{~mL} /$ $\mathrm{min} / \mathrm{g}$, respectively; $\mathrm{P}=0.010$ ) and lower median $\mathrm{CVR}$ during maximum hyperemia $(0.35 \mathrm{mmHg} / \mathrm{min} / \mathrm{mL}$; IQR, $0.29-0.56 \mathrm{mmHg} / \mathrm{min} / \mathrm{mL}$ vs. $0.51 \mathrm{mmHg} / \mathrm{min} / \mathrm{mL}$, IQR, 


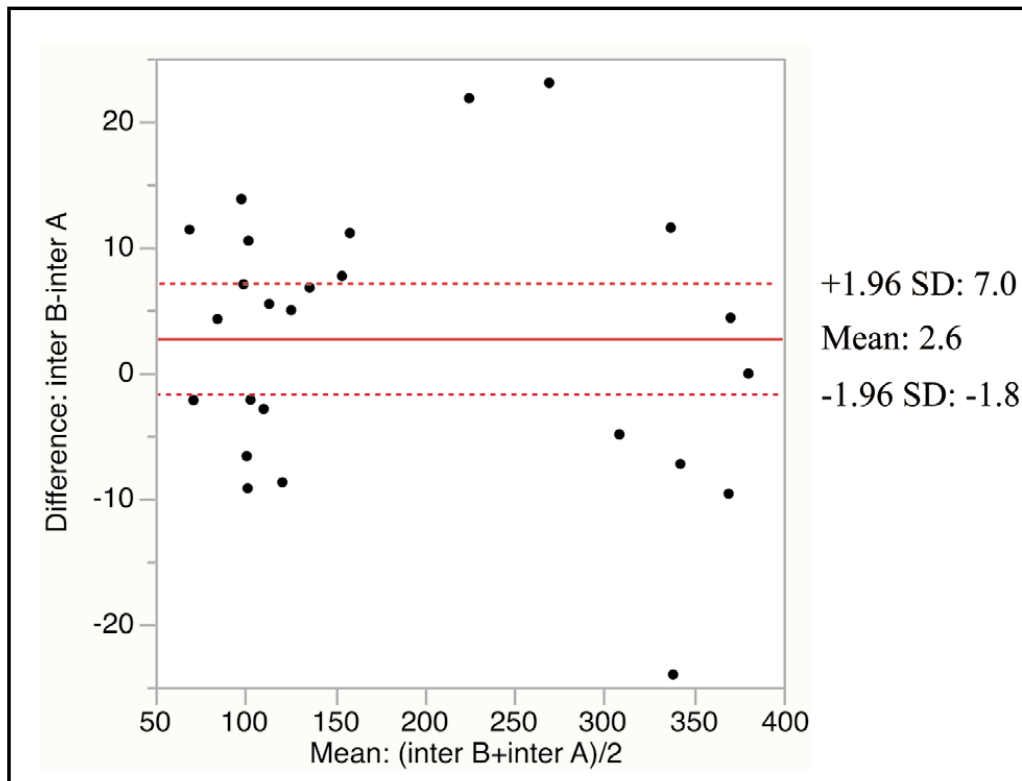

Figure 5. Bland-Altman plot of inter-observer reproducibility of the coronary sinus flow (CSF) measurement ( $\mathrm{mL} / \mathrm{min})$. Horizontal line, bias; dotted lines, $95 \% \mathrm{Cl}$.

$0.37-0.76 \mathrm{mmHg} / \mathrm{min} / \mathrm{mL}$, respectively; $\mathrm{P}=0.043$ ) compared with the CSF increase group. Increased CVR following PCI was observed in the CSF decrease group, leading to significantly higher median CVR compared with the CSF increase group $(0.54 \mathrm{mmHg} / \mathrm{min} / \mathrm{mL}$; IQR, $0.36-0.70 \mathrm{mmHg} / \mathrm{min} / \mathrm{mL}$ vs. $0.31 \mathrm{mmHg} / \mathrm{min} / \mathrm{mL}, \mathrm{IQR}$, $0.25-0.40 \mathrm{mmHg} / \mathrm{min} / \mathrm{mL}$, respectively; $\mathrm{P}=0.006$ ), although there was no difference in median CVR between before and after PCI at the cohort level $(0.46 \mathrm{mmHg} / \mathrm{min} / \mathrm{mL}$; IQR, $0.34-0.62 \mathrm{mmHg} / \mathrm{min} / \mathrm{mL}$ vs. $0.37 \mathrm{mmHg} / \mathrm{min} / \mathrm{mL}$, IQR, $0.25-0.54 \mathrm{mmHg} / \mathrm{min} / \mathrm{mL}$, respectively; $\mathrm{P}=0.067$ ). There was no difference in CFR between the CSF decrease group and the CSF increase group.

Figure 3 shows the relationship between change in CSF and relevant physiological properties. An increase in hyperemic CSF was associated with low hyperemic CSF and high CVR before PCI ( $\mathrm{r}=0.46, \mathrm{P}=0.007 ; \mathrm{r}=0.41, \mathrm{P}=0.017$, respectively). Changes in hyperemic $\mathrm{CSF}$ and $\mathrm{CFR}$ were linearly correlated $(\mathrm{r}=0.39, \mathrm{P}=0.021)$, while there was no relationship of increased FFR with increased hyperemic $\operatorname{CSF}(\mathrm{P}=0.35)$.

\section{Predictors for CSF Decrease}

On multivariate analysis, high pre-PCI CSF during maximum hyperemia was independently associated with decreased hyperemic CSF following PCI (OR, 2.79; 95\% CI: $1.09-8.97, \mathrm{P}=0.031$ per $\mathrm{mL} / \mathrm{min} / \mathrm{g}$ increase; Table 3). On ROC curve analysis for predicting CSF decrease after PCI, the area under the curve was $0.77(\mathrm{P}=0.006$; Figure 4). The best cut-off of pre-PCI hyperemic CSF was $2.65 \mathrm{~mL} / \mathrm{min} / \mathrm{g}$; the corresponding sensitivity, specificity, positive predictive value, negative predictive value and accuracy were $0.69,0.66,0.64,0.80$, and 0.74 , respectively.

\section{CSF Reproducibility}

The reproducibility of CSF measurements was satisfactory for inter-observer reproducibility analysis (ICC, 0.92) and intra-observer reproducibility analysis (ICC, 0.95). Figure 5 shows the Bland-Altman analysis of inter-observer repro- ducibility of CSF during maximum hyperemia.

\section{Discussion}

The main findings of the present study were as follows: (1) PC-CCMR provided CSF representing the absolute LV myocardial flow in a series of 34 patients at rest and during maximum hyperemia both before and after PCI, without significant complications; (2) a decrease in CSF during hyperemia was observed in 13 patients $(38.2 \%)$ after successful PCI, despite increased FFR; (3) hyperemic CSF changes following PCI were linearly correlated with prePCI hyperemic CSF or CVR; and (4) high pre-PCI hyperemic CSF was the only independent predictor for decreased hyperemic CSF following PCI.

In the present study, using PC-CCMR of the CS, which allows non-invasive quantification of $\mathrm{MBF}$ without use of radiation or radioactive tracers, we found that PCI increased the global volumetric myocardial flow in approximately two-thirds of patients receiving uncomplicated elective PCI. Post-PCI Tn elevation was similar between patients with or without increased myocardial flow, indicating that the impact of microembolization and/or coronary spasm on MBF should be minimal. Although we could not completely assess the effect of PCI-related microvascular injury on post-PCI CSF decrease, post-PCI CMR was performed at a median 10 days after PCI, when acute microvascular injury by PCI is considered minimal, and there is no accounting for the observed significant relationship of high pre-PCI CVR with post-PCI increased CSF due to PCI-related microvascular injury. In patients with decreased MBF after PCI, we found a significantly greater pre-PCI hyperemic CSF and lower CVR. Given that all lesions had pre-PCI FFR $\leq 0.80$, patients with decreased CSF after PCI would have non-flow limiting stenosis. Also, given that PCI was performed optimally and without significant complications, the post-PCI hyperemic coronary flow may increase without an effect on epicardial stenosis, provided that there is similar pre- and post-PCI 
hemodynamics and minimized/constant microvascular resistance during hyperemia before and after PCI; the latter is a prerequisite for FFR. $\mathbf{1 3}^{\mathbf{1 3}}$

It remains controversial as to whether hyperemic microvascular resistance in the presence of functionally significant stenosis is equivalent to that after stenosis removal on PCI.,13-17 In support of the present findings, we and others recently reported that successful PCI may not necessarily increase coronary flow (using surrogate markers of coronary flow including flow velocity and mean transit time). ${ }^{14,18}$ The current data clearly show that a minimum and constant hyperemic microvascular resistance may not be applicable before and after PCI, although we did not examine serial changes in regional hyperemic microvascular resistance, but rather global CVR after PCI.

A recent multicenter cohort study proposed an optimal cut-off of hyperemic MBF in PET (for $\left[{ }^{15} \mathrm{O}_{\mathrm{H}} \mathrm{H}_{2} \mathrm{O}\right.$ ) of $2.3 \mathrm{~mL} / \mathrm{min} / \mathrm{min} / \mathrm{g}$ to detect lesions with FFR $\leq 0.8$, while disagreement between hyperemic MBF and FFR data was observed in $25 \%$ of cases, suggesting the presence of nonflow-limiting stenosis. ${ }^{19,20}$ In the present study, in which only lesions with FFR $\leq 0.8$ were included, the median hyperemic pre-PCI $\mathrm{MBF}$ was $3.1 \mathrm{~mL} / \mathrm{min} / \mathrm{g}$ in the flow decrease group. Moreover, pre-PCI hyperemic MBF was the only independent predictor for decreased hyperemic MBF after PCI; these lesions may indicate non-flow limiting stenosis that do not benefit from revascularization in terms of an increased absolute global coronary flow, despite FFR improvement. Further studies are required to clarify the relationship of PCI with both regional and global absolute coronary flow and microvascular status.

\section{Study Limitations}

We prospectively enrolled patients with stable angina pectoris based on symptoms and non-invasive test results, and who were referred to the catheter laboratory for diagnosis or treatment in a single center. The rigorous exclusion criteria for potential CSF measurement confounders or difficulties limited the number of patients, and may have caused selection bias. Although the measurement reliability was acceptable for assessing change in absolute MBF, the current spatial resolution of CMR may have caused partial volume errors, resulting in measurement errors. Given the significant individual variation in $\mathrm{MBF}$ under different hemodynamic states, a larger number of subjects is required to confirm the present findings. Because of the limited sample size, we could not perform extensive subgroup or multivariate analyses or definitive analyses for microvascular and epicardial impairments. Nevertheless, the present results are consistent with prior PET studies, indicating that $\mathrm{MBF}$ was reduced because of microvascular dysfunction, even in territories without significant epicardial stenosis. We also assessed the effect of PCI on global, but not regional, myocardial flow. Further studies are required to examine the effect of PCI of the culprit region on myocardial flow and $\mathrm{CVR}$ in the non-culprit territories. Finally, we performed post-PCI PC-CCMR at a median 10 days (IQR, 8-15 days) after PCI. Further studies are required using a different $\mathrm{CMR}$ time window, and to asses long-term changes in MBF after PCI.

\section{Conclusions}

Global MBF quantification can be achieved on PC-CCMR of the CS before and after PCI. Uncomplicated FFR- guided PCI increased global myocardial flow, although a significant number of patients had decreased MBF, despite FFR improvement after PCI. This suggests a role of microvascular function in determination of post-PCI global hyperemic MBF.

\section{Acknowledgments}

We thank the physicians, nurses, other catheter laboratory staff, and patients involved in this study; and Mr. Tetsuya Komatsuzaki, Mr. Masami Sugiyama, and Mr. Syohei Yamamoto for assistance in acquiring CMR data.

Disclosures

The authors declare no conflicts of interest.

\section{Sources of Funding}

None.

\section{References}

1. Wijns W, Kolh P, Danchin N, Di Mario C, Falk V, Folliguet T, et al. Guidelines on myocardial revascularization. Eur Heart $J$ 2010; 31: 2501-2555.

2. De Bruyne B, Fearon WF, Pijls NH, Barbato E, Tonino P, Piroth Z, et al. Fractional flow reserve-guided PCI for stable coronary artery disease. $N$ Engl J Med 2014; 371: 1208-1217.

3. Kanaji Y, Murai T, Yonetsu T, Usui E, Araki M, Matsuda J, et al. Effect of elective percutaneous coronary intervention on hyperemic absolute coronary blood flow volume and microvascular resistance. Circ Cardiovasc Interv 2017; 10: e005073.

4. van de Hoef TP, Echavarria-Pinto M, van Lavieren MA, Meuwissen M, Serruys PW, Tijssen JG, et al. Diagnostic and prognostic implications of coronary flow capacity: A comprehensive cross-modality physiological concept in ischemic heart disease. JACC Cardiovasc Interv 2015; 8: 1670-1680.

5. Koskenvuo JW, Hartiala JJ, Knuuti J, Sakuma H, Toikka JO, $\mathrm{Komu} \mathrm{M}$, et al. Assessing coronary sinus blood flow in patients with coronary artery disease: A comparison of phase-contrast MR imaging with positron emission tomography. AJR Am J Roentgenol 2001; 177: 1161-1166.

6. Lund GK, Wendland MF, Shimakawa A, Arheden H, Stahlberg F, Higgins CB, et al. Coronary sinus flow measurement by means of velocity-encoded cine MR imaging: Validation by using flow probes in dogs. Radiology 2000; 217: 487-493.

7. Koskenvuo JW, Sakuma H, Niemi P, Toikka JO, Knuuti J, Laine $\mathrm{H}$, et al. Global myocardial blood flow and global flow reserve measurements by MRI and PET are comparable. J Magn Reson Imaging 2001; 13: 361-366.

8. Schwitter J, DeMarco T, Kneifel S, von Schulthess GK, Jorg $\mathrm{MC}$, Arheden $\mathrm{H}$, et al. Magnetic resonance-based assessment of global coronary flow and flow reserve and its relation to left ventricular functional parameters: A comparison with positron emission tomography. Circulation 2000; 101: 2696-2702.

9. Fearon WF, Balsam LB, Farouque HM, Caffarelli AD, Robbins RC, Fitzgerald PJ, et al. Novel index for invasively assessing the coronary microcirculation. Circulation 2003; 107: 3129-3132.

10. Kato S, Saito N, Kirigaya H, Gyotoku D, Iinuma N, Kusakawa $\mathrm{Y}$, et al. Impairment of coronary flow reserve evaluated by phase contrast cine-magnetic resonance imaging in patients with heart failure with preserved ejection fraction. J Am Heart Assoc 2016; 5: $\mathrm{e} 002649$.

11. Siegrist PT, Gaemperli O, Koepfli P, Schepis T, Namdar M, Valenta I, et al. Repeatability of cold pressor test-induced flow increase assessed with $\mathrm{H}(2)(15) \mathrm{O}$ and PET. $J$ Nucl Med 2006; 47: $1420-1426$

12. Watzinger N, Lund GK, Saeed M, Reddy GP, Araoz PA, Yang $\mathrm{M}$, et al. Myocardial blood flow in patients with dilated cardiomyopathy: Quantitative assessment with velocity-encoded cine magnetic resonance imaging of the coronary sinus. J Magn Reson Imaging 2005; 21: 347-353.

13. Murai T, Lee T, Kanaji Y, Matsuda J, Usui E, Araki M, et al. The influence of elective percutaneous coronary intervention on microvascular resistance: A serial assessment using the index of microcirculatory resistance. Am J Physiol Heart Circ Physiol 2016; 311: H520-H531.

14. Murai T, Kanaji Y, Yonetsu T, Lee T, Matsuda J, Usui E, et al. 
Preprocedural fractional flow reserve and microvascular resistance predict increased hyperaemic coronary flow after elective percutaneous coronary intervention. Catheter Cardiovasc Interv 2017; 89: 233-242.

15. Verhoeff BJ, Siebes M, Meuwissen M, Atasever B, Voskuil M, de Winter RJ, et al. Influence of percutaneous coronary intervention on coronary microvascular resistance index. Circulation 2005; 111: $76-82$.

16. Fearon WF. Invasive coronary physiology for assessing intermediate lesions. Circ Cardiovasc Interv 2015; 8: e001942.

17. Yong AS, Ho M, Shah MG, Ng MK, Fearon WF. Coronary microcirculatory resistance is independent of epicardial stenosis. Circ Cardiovasc Interv 2012; 5: 103-108, s101-s102.
18. Matsuda J, Murai T, Kanaji Y, Usui E, Araki M, Niida T, et al. Prevalence and clinical significance of discordant changes in fractional and coronary flow reserve after elective percutaneous coronary intervention. J Am Heart Assoc 2016; 5: e004400.

19. Danad I, Uusitalo V, Kero T, Saraste A, Raijmakers PG, Lammertsma AA, et al. Quantitative assessment of myocardial perfusion in the detection of significant coronary artery disease: Cutoff values and diagnostic accuracy of quantitative [(15)O] H2O PET imaging. J Am Coll Cardiol 2014; 64: 1464-1475.

20. Johnson NP, Kirkeeide RL, Gould KL. Is discordance of coronary flow reserve and fractional flow reserve due to methodology or clinically relevant coronary pathophysiology? JACC Cardiovasc Imaging 2012; 5: 193-202. 